heads of agreement and not just hours of work. If satisfactory solutions are not found because of a shortage of money task forces can report this directly to the ministerial group, which will continue to meet every six months; the government will have to find the necessary resources.

Responsibility for providing information on all aspects of the agreement now lies partly with junior doctors. The BMA has sent its junior members a booklet explaining the new deal in detail, what information is required, and whom to contact for help. ${ }^{6}$ The Secretary of State for Health said when the deal was launched that the resources to achieve the hours deal would be made available. The aspects of the agreement I have referred to must be seen as part of a package of measures which, if implemented with the agreed hours' reductions, should result in improved patient care, improved training for juniors, more efficient working, and perhaps even a few more hot meals at night.

1 NHS Management Executive. Funior doctors. The new deal. London: NHS Management Executive, 1991.

2 NHS Management Executive. Funior doctors. The newo deal. Making the best use of the skills of nurses and midwives. London: NHS Management Executive, 1991.

3 NHS Management Executive. Funior doctors. The new deal. Making better use of technical, administrative, clerical, and other support staff and systems. London: NHS Management Executive, 1991.

4 University of London. Inappropriate duties for preregistration house officers. London: University of London, 1991.

5 NHS Management Executive. Funior doctors. The new deal. Living and working conditions of doctors in training. London: NHS Management Erecutive, 1991. 6 BMA Junior Doctors Committee. Funior doctors. The new deal. London: BMA,
1991 .

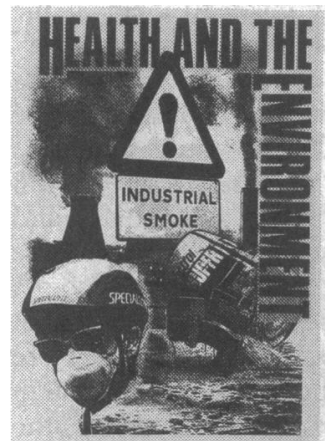

This is the first in a series of articles which examine the impact of environmental pollution on human health.

British Medical Journal, London WC1H 9JR

Fiona Godlee, MRCP, assistant editor

Alison Walker, MRCP, former editorial registrar

Correspondence to: $\mathrm{Dr}$ Godlee.

BMF 1991;303:1124-6

\section{Health and the Environment}

\section{Importance of a healthy environment}

\author{
Fiona Godlee, Alison Walker
}

Doctors seem to spend their time these days exhorting their patients to adopt healthier habits: to exercise more, eat less, drink only a little and smoke not at all; to wear seat belts, crash helmets, and condoms. But perhaps the most important risks to health are beyond people's immediate control, caused by the unhealthy habits not of individuals but of an energy hungry and throwaway society.

\section{The environmental price}

Since the industrial revolution and the advent of the internal combustion engine we have consumed the earth's natural resources and altered our environment at a rate never seen before. The demand for energy is constantly growing, fuelled by the world's escalating population - now at 5.3 billion and estimated to reach 10 billion by $2050 . .^{1}$ In 1989 the world's energy consumption reached $9 \cdot 3$ million tons of oil equivalent, causing the emission of nearly six billion tons of carbon into the environment (figure). ${ }^{2}$ The World Energy Conference concluded that by 2020 the world would be using $75 \%$ more energy, and most of it would still be supplied by coal, oil, and nuclear power. ${ }^{3}$

The destructive consequences of human industry on the environment are in many cases already evident, in others controversial. Chlorofluorocarbons, still used as a propellant in aerosols in some countries and in the manufacture of refrigerators, are destroying the layer of ozone in the outer atmosphere which protects the earth from the sun's ultraviolet rays. If levels of chlorofluorocarbons continue to rise at the present rate-about $3 \%$ a year $-\mathrm{a} 6 \%$ reduction in stratospheric ozone has been predicted by $2040 .^{4}$ The resultant increase in the amount of ultraviolet $B$ reaching the earth's surface $-1 \cdot 5-2 \%$ for every $1 \%$ reduction in total column ozone-has the potential to cause ecological catastrophe. Phytoplankton, for example, the basis of the food chain for all aquatic creatures, are highly vulnerable to damage from ultraviolet B radiation. ${ }^{5}$

Greenhouse gases-carbon dioxide from the burning of fossil fuels, methane, nitrous oxide, and chlorofluorocarbons-are accumulating in the outer atmosphere, where concentrations of carbon dioxide are now higher than at any time in the past 16000 years. ${ }^{6}$ Global warming may be the consequence. The earth's surface temperature has risen by about $0 \cdot 6^{\circ} \mathrm{C}$ in the past 100 years and further increases of $2-5^{\circ} \mathrm{C}$ have been predicted over the next 50 to 100 years, causing potentially catastrophic rises in sea level. ${ }^{\text {s }}$

Road vehicles, responsible for emitting a fifth of the carbon dioxide in air, also produce acidic gasesnitrogen oxides and sulphur dioxide-which cause acid rain. Though heavy industry is bringing its emissions under control, the use of road transport is increasing at a rate likely to swamp any reductions in pollution achieved by technological improvements in car engines. The Department of Transport estimates that in Britain the number of vehicle miles will double by 2025 , causing an estimated doubling of emissions of carbon dioxide. ${ }^{7}$ For the same reason emissions of nitrogen oxides, which will fall over the next 20 years owing to the introduction of catalytic converters, will be on the increase again by 2020 .

Acid rain lays waste large areas of agricultural land and forest, adding to deforestation caused by harvesting hardwood and the pressure for more agricultural land. Each year an area of tropical forest the size of Austria is destroyed. ${ }^{1}$ Deforestation increases the build up of carbon dioxide because trees fix carbon from the air. It also spells disaster for biological diversity as more than half the species on earth live in the tropical rain forests. $^{8}$

\section{The human price}

Man, the main cause of environmental degradation, is also one of its victims. Apart from the direct effects that increases in ambient temperature might have on health - higher mortality from heart and lung disease; the spread of tropical diseases to temperate climates; more deaths, disability, and psychological problems due to storms and natural disasters-global warming would cause the sea to expand and swamp large areas of habitable and agricultural land. ${ }^{9}$ A rise in sea level of one metre (the International Panel on Climate Change's 1990 estimate $^{10}$ ) would cover five million square kilometres of the world's lowest lying land, causing the loss of one third of our crop growing areas and creating 50 million environmental refugees.

Nuclear energy reduces reliance on fossil fuels but creates problems of its own. The fire at Chernobyl nuclear power station in 1986 is still having repercus- 


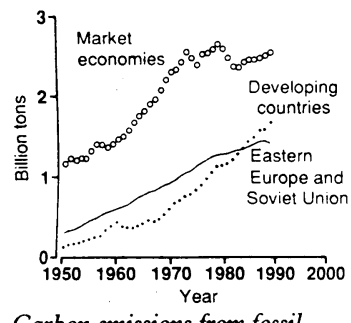

Carbon emissions from fossil fuels 1950-1989. From "State of the World 1991" sions in parts of Europe, and smaller leaks of radiation are a cause of anxiety following reports of clusters of leukaemia in children living near nuclear installations in Britain. ${ }^{11-13}$

Thinning of the ozone layer will increase the incidence of sun related skin cancers. A $10 \%$ reduction in total column ozone-possible by the late twenty first century if levels of chlorofluorocarbons continue to increase at their present rate-could result in an extra 160000 cases of non-melanocytic skin cancer in the United States each year and an extra 4000 deaths from malignant melanoma. ${ }^{14}$ At the moment the incidence of melanoma in the United States is a quarter the incidence in Queensland, Australia, where about one in every 150 white males dies of the disease.

Man's love affair with the motor car is also turning sour. City smogs, once thought to be a thing of the past, are back again. The impenetrable pea soupers, such as the one which enveloped London in December 1952 , killing 4000 people, ${ }^{15}$ were caused by domestic and industrial burning of high sulphur coal. In their place there is now an invisible cocktail of pollutants emitted from road vehicles, many of which are known to be harmful to health. ${ }^{16}$ Nitrogen dioxide and sulphur dioxide are respiratory irritants. They are the main constituents of acid rain and exacerbate asthma and chronic lung disease. Airborne particulates, emitted mainly from diesel vehicles and visible in the air as black smoke, are inhaled into the lungs and carry with them acidic gases and volatile organic compounds such as benzene, which is a known carcinogen. Ozone at ground level, produced by the effects of sunlight on traffic fumes, causes impaired lung function, and there is some evidence that the increase in air pollution over the past 40 years could be responsible for an increase in the number of admissions to hospital and deaths caused by asthma. ${ }^{17}$

The waste products of industrial processes, domestic consumption, and transport are creating further health risks. In England and Wales alone some 25000 million tonnes of waste are disposed of every year, about $90 \%$ of which ends up in one of the 4000 controlled landfill sites around the country. ${ }^{18}$ There have not been many studies on the health risks associated with waste disposal, but there is some evidence that refuse workers are at increased risk of illness. ${ }^{19}$

Air pollution, ozone depletion, land degradation, acid rain, and altered rainfall patterns have caused a reduction in world harvests and fears of a world food crisis. The world's grain harvest currently increases by an average of 15 million tonnes each year. ${ }^{9}$ This is already well below the 28 million tonne increase needed to keep pace with population growth. But if current rates of environmental degradation continue, the world's grain harvest could fall by about 14 million tonnes each year. Famine stricken countries that rely on food imports from the West are the most at riskand the least able to manage.

\section{Reversing the damage}

Reversing damage to the environment will take time. It is not just a question of removing the remaining sources of pollution but of dealing with the stockpile of pollutants that have accumulated over the years. Toxins in landfill sites, for example, continue to leach slowly into ground water, and non-biodegradable pesticides are still working their way down the food chain.

It may not be possible to reverse the damage in our lifetime or even that of our children and grandchildren. Carbon dioxide and chlorofluorocarbons, both of which have long half lives, persist in the atmosphere long after they are produced. Half of the carbon The beach is no longer a safe place to play

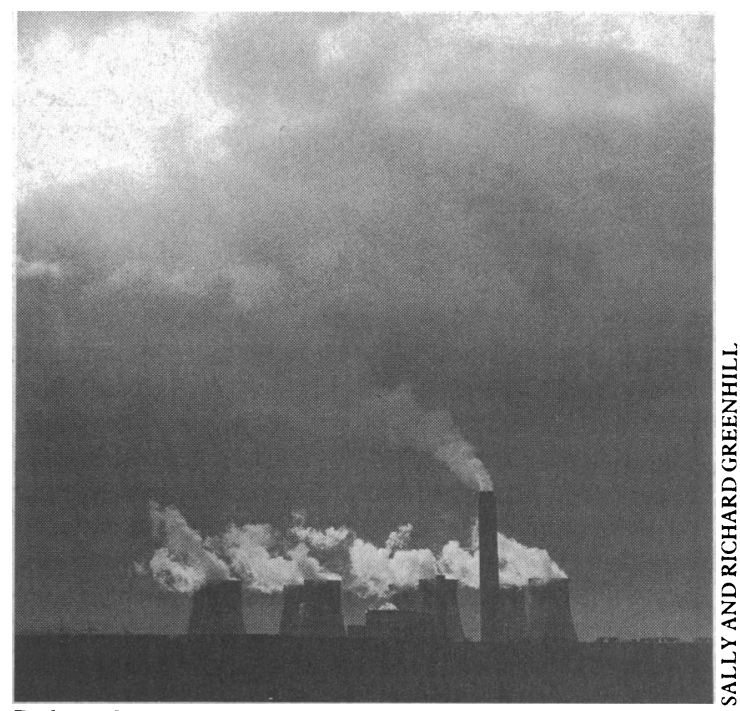

Perhaps the most important risks to health are caused by an energy hungry society

lution remains in the atmosphere today ${ }^{6}$ Chlorofluorocarbons linger for 50 to 100 years before they are broken down, and even with reductions in emissions in line with the Montreal protocol, active chlorine levels in the stratosphere will roughly double by $2040 .{ }^{20}$ Alternatives to both chlorofluorocarbons and the burning of fossil fuels already exist, but adopting them on a worldwide scale requires planning and financial investment. Countries in the Third World are recent converts to cars, tin cans, and aerosol sprays. Increasingly in debt to the West, they cannot afford to modernise their now outdated technology. They will need help to make the switch to more environmentally friendly methods.

As the paths of the rich and poor nations continue to diverge the task of controlling the world's population will become more, not less, difficult. The population of western Europe is falling. By the end of the century only $20 \%$ of the world's population will be living in developed countries. ${ }^{21}$ But the ability to limit family size stems partly from the knowledge that children will survive to adulthood. In developing countries family planning must be accompanied by efforts to reduce child mortality and improve the health of women.

For many people in the West environmental priorities are quite different. They have shifted from global issues to the luxury of questioning the quality of tap water or the level of air pollution in cities. While scientists continue to argue that tap water in Britain is just as safe today as it was 50 years ago, the public expresses its doubts by buying bottled water at 1000 times the price. Sales of bottled mineral water increased from three million to 128 million litres between 1976 and $1986 . .^{22}$

Epidemiological evidence to confirm or refute the public's fears about the safety of tap water is largely lacking, but some aspects of environmental research are coming up with answers. Swimming in sea water contaminated by raw sewage has been shown, through a number of studies since the 1970 s, to be associated with increased risk of gastrointestinal symptoms and ear, nose, and throat infections..$^{23}$ As a result efforts are now being made to clean up beaches in Britain and Europe, prompted by European Community directives and the fear of losing income from tourists.

\section{Quality of the evidence}

It would be nice to be able to say with certainty that $x$ amount of air pollutant causes $y$ additional cases of asthma each year. Unfortunately, when it comes to environmental pollution it is not quite so simple. 


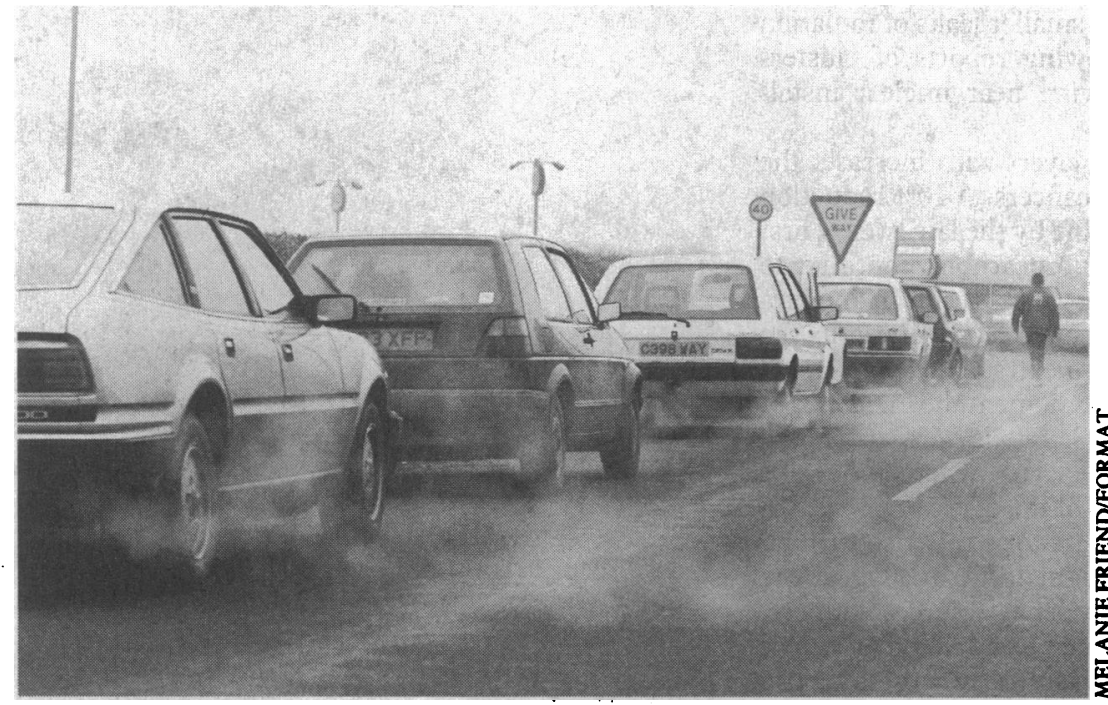

Man's love affair with the motor car is turning sour
Predictions about global warming and ozone depletion are based on mathematical models, which are open to question. Equally uncertain are estimates of the effects on health of chemical pollutants, airborne carcinogens, and radiation in the environment. These are largely based on the evidence of occupational studies and "natural" disasters such as the explosion of the atomic bomb in Hiroshima and the accidental contamination of the water supply with aluminium sulphate at the Lowermoor works in Camelford in 1988. But there are problems in extrapolating from acute, high dose exposure to chronic, low dose, environmental exposure. Large scale population studies that should circumvent these problems are often flawed by, for example, the difficulty of finding control subjects who have not also been exposed to the environmental pollutant.

Over the next few weeks we will examine the risks to human health from environmental pollution. Starting with the population growth which primes the pump, we will then consider the possible impact of climatic change due to global warming and the destruction of the ozone layer. Subsequent articles will deal with the related issues of air pollution, transport, and environmental noise and with the quality of drinking water, the standard of beaches, and the disposal of sewage and hazardous waste. Finally we will ask if radiation in the environment, whether natural or man made, is dangerous to health.

These questions are of great importance to doctors. Understanding the effects of the environment on health allows the practice of perhaps the ultimate in preventive medicine. We may already be treating health problems related to environmental pollution: asthma and bronchitis from city smogs, gastrointestinal and ear infections from polluted sea water, hearing loss and psychological problems caused by environmental noise. Some questions remain unanswered. Does air pollution cause lung cancer? Is the nuclear industry the cause of leukaemia clusters in children? What are the risks from contaminated drinking water and radon in homes? Patients are increasingly well informed on these issues, but they expect doctors to provide information and advice. Doctors are in a prime position not only to monitor the effects of environmental pollution on their patients but to change the

behaviour of individuals and those in authority. It is only through radical change that environmental degradation and its damaging effects on human health will be halted.

1 United Nations Population Fund. The state of world population 1991. New York: United Nations Population Fund, 1991.

2 Brown LR. The new world order. In: Brown LR, ed. State of the world 1991. A Worldwatch Institute report on progress toward a sustainable society. London: Earthscan Publications, 1991.

3 Flavin C, Lenssen N. Designing a sustainable energy system. In: Brown LR;ed. State of the world 1991. A Worldwatch Institute report on progress toward

sustainable saciety. London: Earthscan Publications, 1991.

Watson RT. Present state of knowledge of the ozone layer. In: Russell Jones R, Wigley T, eds. Orone depletion: health and environmental consequences. Chichester: Wiley, 1989.

5 Leaf A. Potential health effects of global climatic and environmental changes. N Engl Y Med 1989;321:1577-83.

6 Brown LR, ed. State of the world 1989: a Worldwatch Institute report on progress toward a sustainable society. New York: W W Norton, 1989.

7 Fergusson M, Holman C, Barrett M. Atmospheric emissions from the use of transport in the UK. Vol 1. The estimation of current and future emissions. London: World Wildlife Fund and Earth Resources Research, 1989.

8 Wilson EO. Threats to biodiversity. Sci Am 1989;261:108-16.

9 Haines A. Potential impacts on health of atmospheric change. $f$ Public Health Med 1991;13:000-00.

10 Houghton JT, Jenkins GJ, Ephraums JJ. Climate change-the IPCC scientific assessment. Cambridge: Cambridge University Press, 1990.

11 Independent Advisory Group. Investigation of the possible increased incidence of cancer in West Cumbria. London: HMSO, 1984. (Black report.)

12 Committee on Medical Aspects of Radiation in the Environment. Investigation Committee on Medical Aspects of Radiation in the Environment. Investigation
of the possible increased incidence of leukaemia in young people near the Dounreay of the possible increased incidence of leukaemia in young people near the Dound,

13 Committee on Medical Aspects of Radiation in the Environment. Report on the incidence of childhood cancer in the west Berkshire and north Hampshire area, in which are situated the Atomic Weapons Research Establishment, Aldermaston and the Royal Ordnance Factory, Burghfield. London: HMSO, 1989.

14 Russell Jones R. Consequences for human health of stratospheric ozone depletion. In: Russell Jones, Wigley T, eds. Ozone depletion: health and environmental consequences. Chichester: Wiley, 1989.

15 Ministry of Health. Mortality and morbidity during the London fog of December 1952. London: HMSO, 1954.

16 World Health Organisation. Air quality guidelines for Europe. Copenhagen: WHO Regional Publications, 1987.

17 Read C. Air pollution and health. London: Greenpeace, 1991.

18 British Medical Association. Hazardous waste and human health. Oxford: Oxford University Press, 1991.

19 Gustavsson P. Mortality among workers at a municipal waste incinerator. Am $\mathcal{F}$ Ind Med 1989;15:245-53.

20 Elman RS, Pyle JA. Numerical modelling of ozone perturbations. In: Russell Jones R, Wigley T, eds. Ozone depletion: health and environmental Jones R, Wigley T, eds. Ozone
consequences. Chichester: Wiley, 1989.

21 United Nations Department of International Economic and Social Affairs. World population at the tum of the century. New York: United Nations, 1989.

22 Wheeler D. Risk assessment and the public perception of water quality. Annual symposium of the Institution of Water and Environmental Management. London, 1990:2-1-2-13.

23 Pike EB. Health effects of sea bathing. Phase 1 - pilot study at Langland Bay. Medmenham: Water Research Centre, 1990. (Report DoE 2518 M(P).)

\section{ANY QUESTIONS}

What are the causes, precipitative factors, and treatment of night terrors?

Night terrors occur chiefly in young preschool children, often, but not always, after psychological trauma. They differ from nightmares in that they occur in stage four sleep, whereas nightmares occur during stage one (REM) sleep, and children do not recall their content on awakening, whereas they readily retail a nightmare. The child usually seems to awaken at the same time each night and to be terrified, his eyes open widely, staring and screaming loudly. He does not seem to recognise his parents or others and is not comforted by their presence. The night terrors may be associated with sleepwalking. They may disappear as abruptly as they came. They can be abolished by large doses of diazepam given for no longer than one week (5-30 $\mathrm{mg}$ according to size), but recently a less toxic treatment has been reported as effective. ${ }^{1}$ The child is awakened about 10 minutes before the usual time of his terror, and this is done regularly for about two weeks. It is effective in most cases in restoring a normal sleep pattern. If the child has experienced traumatic events he may also need psychiatric assessment and treatment and should be referred to a child psychiatrist if simple measures such as those described above are not successful. - DORA BLACK, consultant child and adolescent psychiatrist, London

1 Lask B. A novel and non-toxic treatment for night terrors. $B M \mathcal{F}$ 1988;297:5922. 